\title{
Geometric morphometrics reveal relationship between cut- mark morphology and cutting tools
}

\author{
Francesco Boschin ${ }^{1}$, Erika Moretti ${ }^{1}$, Jacopo Crezzini $^{1}$, Simona Arrighi ${ }^{2}$ \\ ${ }^{1}$ Dipartimento di Scienze Fisiche, della Terra e dell'Ambiente, UR Ecologia Preistorica/ Università degli Studi di Siena, via Laterina 8,53100 \\ Siena, Italy \\ 2 Dipartimento di Beni Culturali/ Università di Bologna, via degli Ariani 1 48121, Ravenna, Italy
}

\begin{abstract}
The analysis of bone-surface modifications (BSM), such as butchering marks, is necessary to better understand how the exploitation of animal resources by past hominins influenced their biological and cultural evolution. In this paper, we try to quantify to what extent the depth of the cut marks influences the shape of their cross sections. This is of crucial importance for a valid interpretation of the shape data collected on archaeological BSMs. Two groups of slicing cut-mark cross sections were experimentally produced with two flint burins on a defleshed cattle innominate, and a set of butchering marks were produced with an unretouched flint flake. These were analysed by means of 3D microscopy and geometric morphometrics. The resulting sets of striae show different depths and different crosssectional shapes. Shallower cross sections display less steep walls and, consequently, a wider opening angle. When the characteristics of the burin cutting edges were investigated, it was clear that the difference in shape between the two groups of striations was probably a function of the way in which the tool penetrated the bone. These results are taphonomically relevant since similar differences in crosssectional shapes have been found in marks produced with different tools.
\end{abstract}

\section{Section: RESEARCH PAPER}

Keywords: geometrics morphometrics; 3D microscopy; taphonomy; bone surface modifications; lithic tools

Citation: Francesco Boschin, Erika Moretti, Jacopo Crezzini, Simona Arrighi, Geometric morphometrics reveal relationship between cut-mark morphology and cutting tools, Acta IMEKO, vol. 10, no. 1, article 14, March 2021, identifier: IMEKO-ACTA-10 (2021)-01-14

Editor: Carlo Carobbi, University of Florence, Italy

Received April 30, 2020; In final form October 4, 2020; Published March 2021

Copyright: This is an open-access article distributed under the terms of the Creative Commons Attribution 3.0 License, which permits unrestricted use, distribution, and reproduction in any medium, provided the original author and source are credited.

Corresponding author: Simona Arrighi, e-mail: s.arrighi@hotmail.com

\section{INTRODUCTION}

The application of 3D imaging in taphonomy has increased in recent years. These studies are often aimed at analysing bonesurface modifications (BSM), such as butchering marks, gnawing marks or modifications due to trampling and abrasion caused by sediments [1]-[6]. The aim of such taphonomic studies is to better understand hominin behaviour through time [7]-[10]. At the University of Siena, 3D imaging has been applied to the study of BSMs since 2009 using a Hirox KH-7700 digital microscope [2]-[4], [9], [11], [12]. A first pilot study, inspired by results achieved by colleagues [1], focused on the distinction between the cut-mark cross sections (i.e. elongated striations on the bone surfaces) produced with different tools (metal knives and retouched/unretouched flint implements). The obtained results [2] demonstrated how a morphometrical approach can be useful to characterise and study cross sections of BSMs from archaeological sites. In addition, it demonstrated that the analysis of only one median cross section per mark can be enough to separate different sets of striae. Further research has been carried out to understand how specific tools and actions could influence the morphology and morphometry of cut-mark cross sections [3], [4]. In particular, it has been observed that the same 'category' of lithic implement (for instance, an unretouched flint flake) can leave different traces when used for different tasks, such as for butchery activities or for the production of engraved art objects on flat bones [4]. At the same time, other research groups have begun to use geometric morphometrics to distinguish different types of BSMs, achieving interesting results [7], [13]-[16]. In this paper, we use a geometric morphometric approach to analyse the cross sections of two sets of incisions, produced in two previous experimental works, in order to evaluate the cross-sectional variability of the traces produced by similar lithic implements (two burins) [4] and by an unretouched flint flake [2]. The aim of this contribution is to link the characteristics of the grooves to those of the cutting edges of the tools used. 


\section{MATERIALS AND METHODS}

In this work we analysed slicing cut marks produced with two burins and an unretouched flint flake. The three experimental lithic implements were made from the same raw material (flint from the Gargano promontory, south-eastern Italy). A set of three striations was produced with each burin on the flat, defleshed surface of a cattle innominate. Since the production of the striations was the goal of this experiment, we maintained control over the type of active edge that inflicted the marks on the bone, a trihedral (Figure 1 A). Furthermore, in this paper we take into consideration an additional set of 22 striations produced in 2010 during a butchery experiment, carried out on a cattle autopodium (metapodial and phalanges), using an unretouched flint flake [2]. The autopodium was fresh, with all the soft tissues still attached to the bones. The aim of this
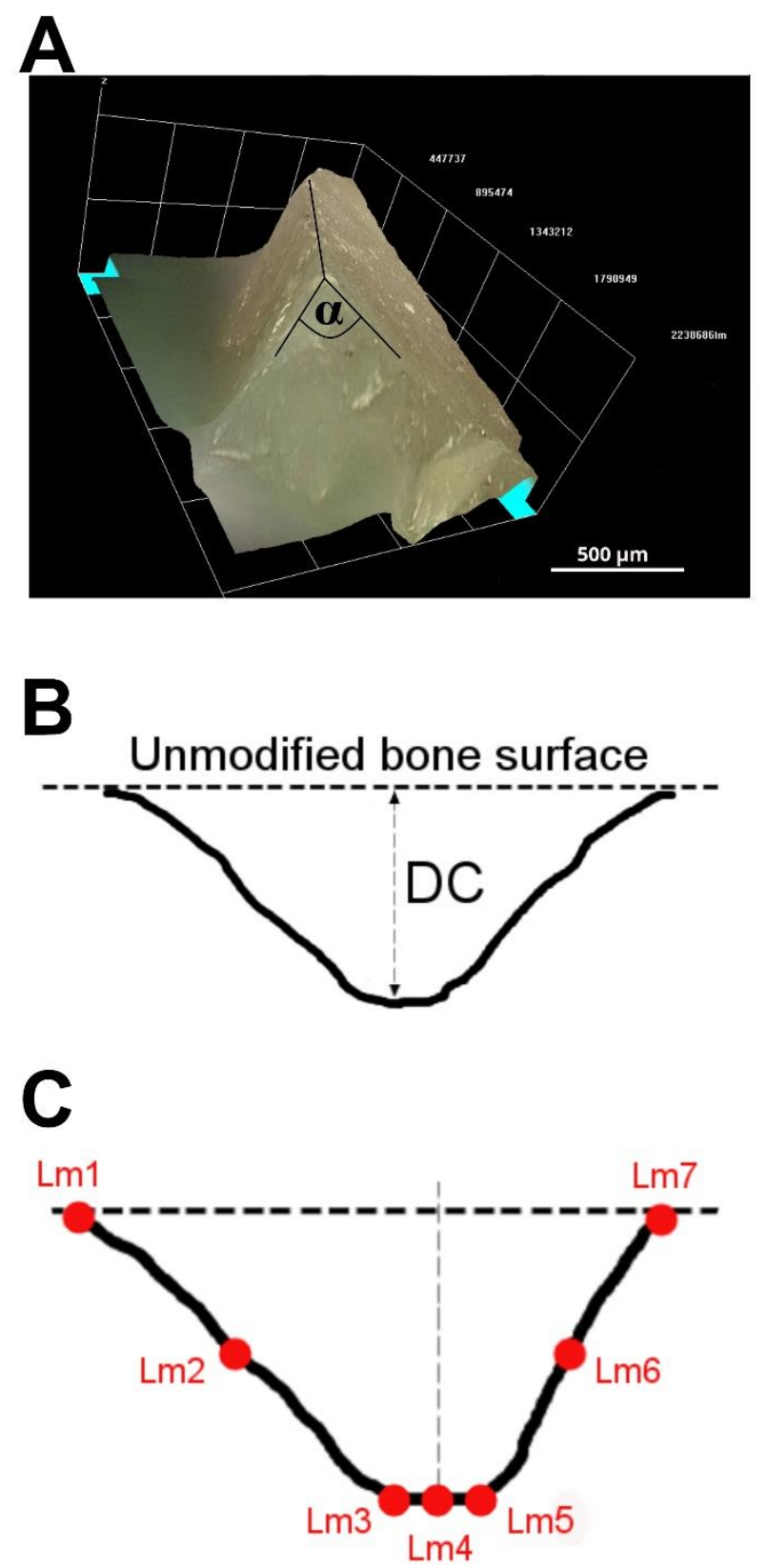

Figure 1. A: 3D image of the active edge of the burins; $B$ : depth of the cut measured in the cross sections; $\mathrm{C}$ : landmarks placed on the cross sections. experiment was the butchering itself, while the production of cut marks should be considered a collateral effect. This means that the operator had no control over the exact portion of the tool's active edge that inflicted the marks. This set of striations is similar to those found in archaeology due to the lack of information on the tool used by the butcherer. The active edge of the burins and all the cut marks were scanned by means of a Hirox KH-7700 digital microscope, equipped with an MXG-10C body, an OL-140II lens and an AD-10S Directional Lighting Adapter [2], [4], [17]. Angle $\alpha$ was measured on the 3D model of the active edge of each burin (Figure $1 \mathrm{~A}$ ). Three cross sections were analysed per mark produced with the burins (taken respectively at $25 \%, 50 \%$ and $75 \%$ of the mark's length), while only the cross section taken at $50 \%$ of the mark's length was available for the striations inflicted with the flint flake. The depth of cut (DC) [1], [2] was measured on each profile (Figure 1 B) and seven landmarks were placed on each cross section, as described in [10] (Figure 1 C), using tpsUtil (v. 1.58) and tpsDig (v. 2.17) software [18], [19]. The raw coordinates of the landmarks were imported into MorphoJ software (v. 1.8) [20]. After a Procrustes fit and the generation of a covariance matrix, a principal component analysis was performed on the dataset.

\section{RESULTS}

The grooves produced on the bone by the burins show some differences in relation to what are usually referred to as 'slicing cut marks' (as defined by Greenfield [21]); the starting and ending points are sometimes abrupt. This is because the operator produced grooves of a prearranged length and the applied force did not change significantly from the starting point to the median section and the ending. For this reason, the morphological characteristics of the starting/ending points of the grooves are not important for this study. An example of how two grooves start and end is shown in Figure 2.

The grooves produced with the two burins show a significant difference in DC (Mann-Whitney U test, $p=0.006$ ). Deeper cuts were inflicted using Burin 2, with DC ranging between $58.7 \mu \mathrm{m}$ and $86.9 \mu \mathrm{m}$. In comparison, the DC of the marks produced with Burin 1 are between $26.6 \mu \mathrm{m}$ and $78.7 \mu \mathrm{m}$ (Figure 3). Having used the same kind of tool, produced with the same raw material, and with the tools being applied on the same surface, this difference must be due to the difference in force adopted by the operator, as has already been observed during other tests [3].

Geometric morphometric analysis is able to discriminate between the cut marks produced with the two burins. In particular, the two groups of cut marks, Burin 1 (B1) and Burin 2 (B2), are differently distributed along principal component 2 (PC2), which describes $31.5 \%$ of the sample's variance. The values of group B2 are significantly higher than those of group B1 (Mann-Whitney U test, $p=0.0005$ ), indicating deeper cross sections with steeper walls (Figure 4a). The difference in shape between the two groups can be easily seen with the Procrustes analysis shown in Figure 4b and 4c. Whereas PC1 is not able to distinguish the two groups, it describes $54.8 \%$ of the sample's variance, and it is better related to the symmetry of the cross sections. 

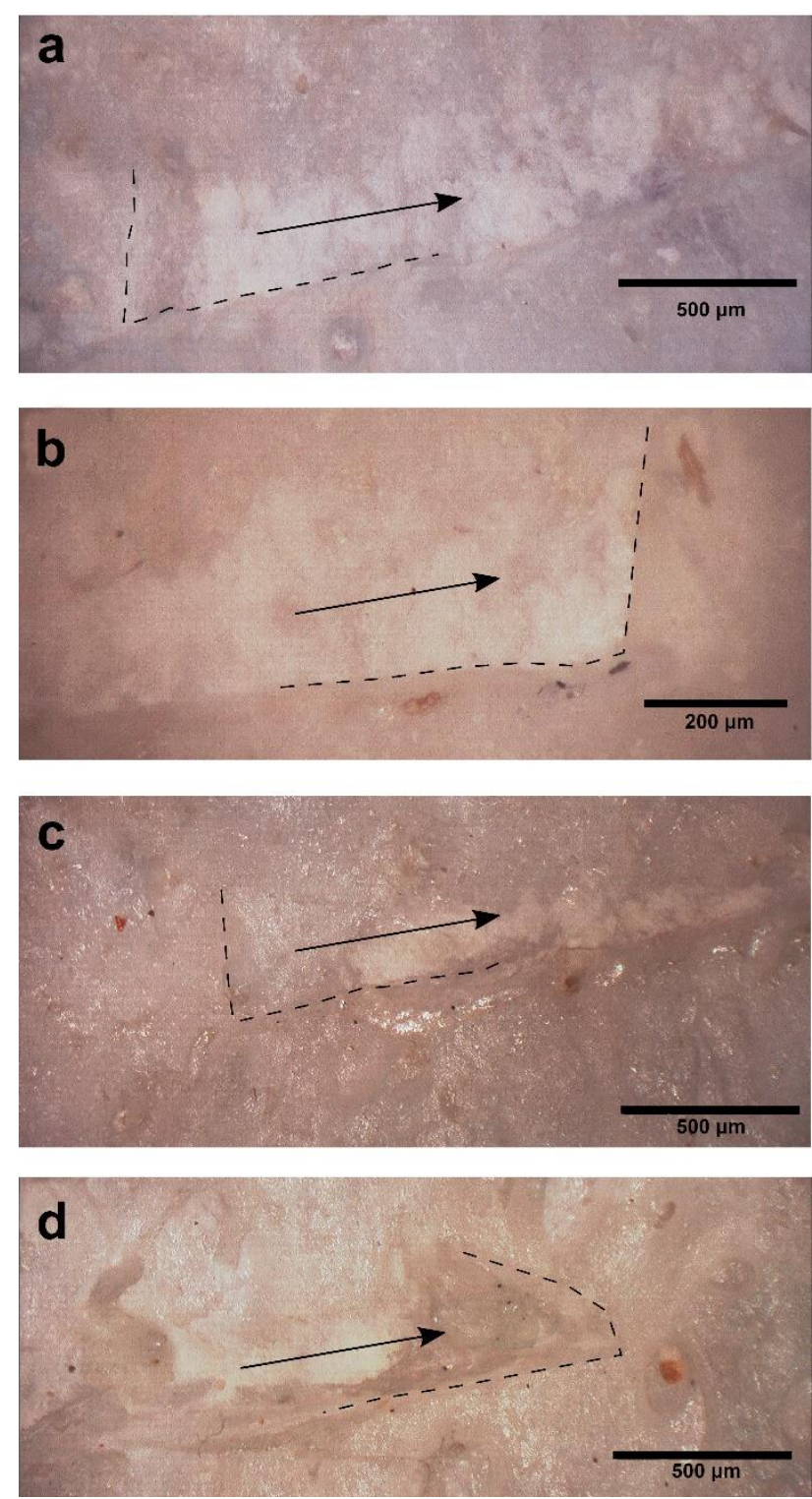

Figure 2. a, b: starting and ending points of a groove produced with Burin 1; c, d: starting and ending points of a groove produced with Burin 2. Dotted lines indicate the abrupt edges of the groove; arrows indicate the direction of the hand movement.

In terms of the analysis of the 3D models of the active edges, which were used to inflict the cut marks, it emerges that angle $\alpha$ is generally wider towards the top of the edge. In B1, the angle between the two surfaces that form the cutting edge is $119.6^{\circ} \pm$ $1.3^{\circ}$, if only the first $30 \mu \mathrm{m}$ are considered, $96.9^{\circ} \pm 0.7^{\circ}$, if we consider a depth of $60 \mu \mathrm{m}$, and $82.3^{\circ} \pm 0.8^{\circ}$, if we consider a depth of $85 \mu \mathrm{m}$. These values are respectively $120.6^{\circ} \pm 0.7^{\circ}$, $109.8^{\circ} \pm 0.8^{\circ}$ and $98^{\circ} \pm 0.5^{\circ}$ in B2. Figure 5 a shows more clearly how the angle changes when different depths of penetration of the tools' edge into the bone tissue are taken into consideration. This could imply that the general shape of the cross sections of a cut mark depends on the penetration of the cutting edge into the bone tissue (as exemplified in Figure 5b). Both principal components show a positive and significant linear correlation with DC: the $p$-value is 0.0001 for PC1 and 0.0004 for PC2.

Geometric morphometrics revealed that the grooves inflicted with the unretouched flint flake exhibited considerably greater variability in shape than the striations produced with the burins. These grooves are described by three main principal

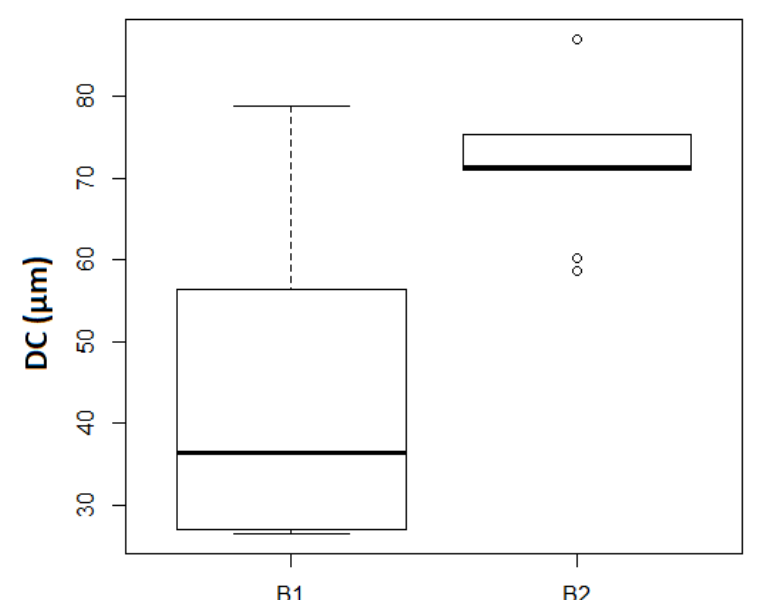

Figure 3. Depth of cross sections (DC) according to which burin was used (B1: Burin 1; B2: Burin 2).

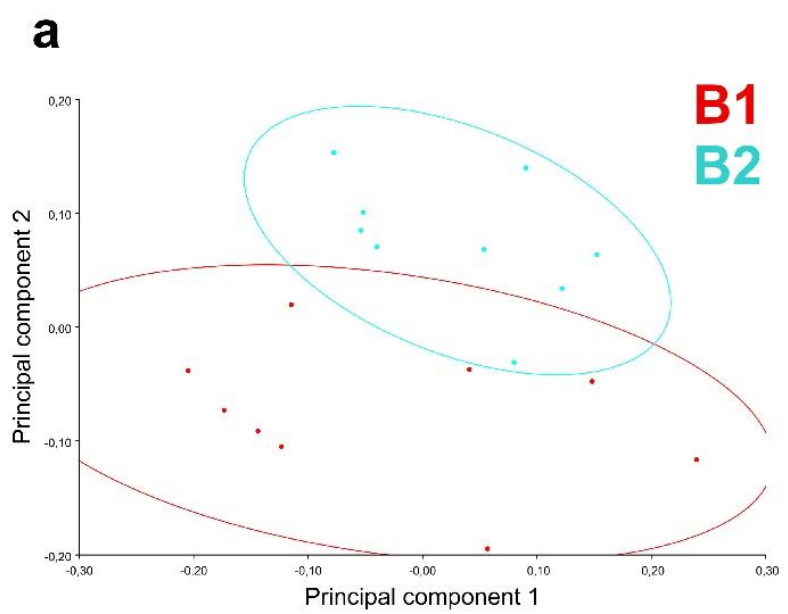

b

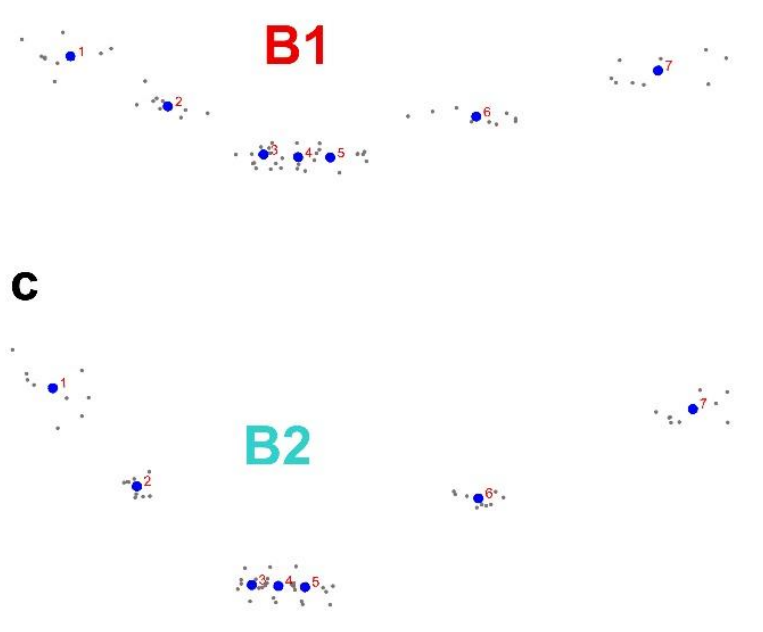

Figure 4. a: PCA performed on the covariance matrix after a Procrustes superimposition. b: Procrustes analysis on the 'Burin 1' group. c: Procrustes analysis on the 'Burin 2' group. 
A
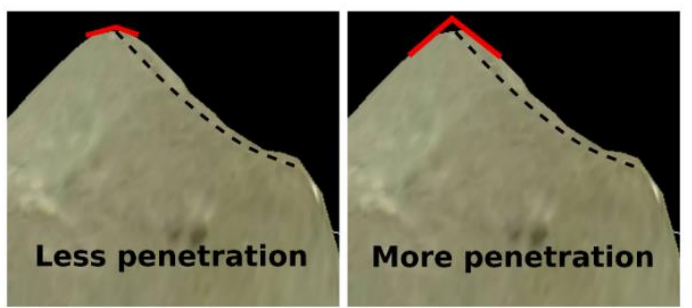

B
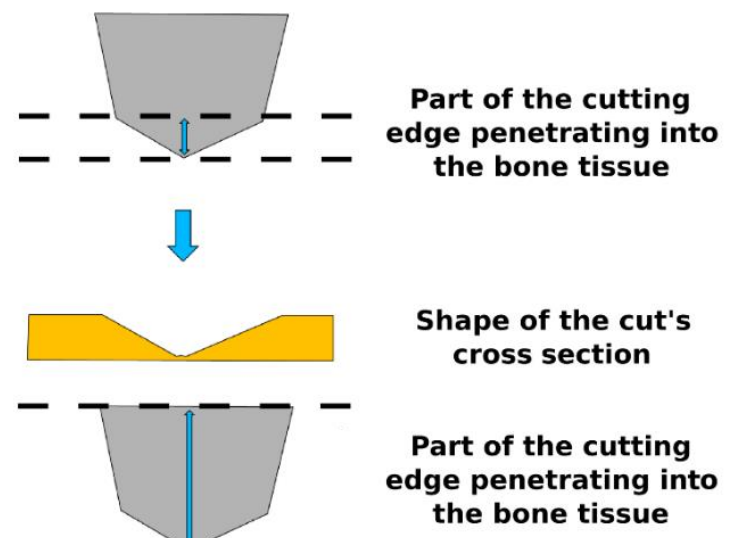

Shape of the cut's cross section

\section{Part of the cutting edge penetrating into the bone tissue}

\section{Shape of the cut's cross section}

Figure 5.: An example of how angle $\alpha$ changes according to the penetration of the cutting edge into the bone tissue. Dotted line: cutting edge. Red lines: angle $\alpha$ when only $20 \mu \mathrm{m}$ of flint penetrates into the bone tissue (left) and when $80 \mu \mathrm{m}$ of flint penetrates into the bone tissue (right). b: schematic sketch explaining the possible influence of the cutting edge on the mark's cross section, depending on the intensity of the penetration.

components, PC1, PC2 and PC3 (which accounted respectively for $41.7 \%, 34.4 \%$ and $17.5 \%$ of the variability). PC1 could be interpreted as a function of the symmetry of the cross section and PC2 as a function of the presence of slopes or ancillary striations on the slopes of the cross sections. PC3 could be interpreted as a function of the depth and is related to the open angle of the cross sections (shallower cuts with wider open angles vs deeper cuts with smaller open angles); it is only PC3 that shows a significant (and positive) correlation with DC ( $p=0.01)$

Finally, a principal component analysis was performed by combining the two experiments. In doing so, we considered only the cross section taken at $50 \%$ of the mark's length for all the striations. In this case, the variability is still described by three main principal components. Of these, PC2 and PC3, which together describe $54.3 \%$ of the sample's variability (PC2 accounted for $35.1 \%$ and PC3 accounted for $19.2 \%$ ), are related to the DC (PC2: $p=0.002$; PC3: $p=0.02$ ). The interpretation of these two components is the same as that for PC2 and PC 3 in the previous analysis (shape of the slopes and open angle, Figure 6).

\section{DISCUSSION AND CONCLUSION}

Data presented in this paper demonstrate how the shape of the mark's cross sections can depend on the level of penetration of the cutting edge into the bone tissue. It also highlights the importance of combining shape data from geometric morphometrics with linear measurements (here the DC). Despite the small sample size, the results of our analysis show that the depth of a striation can influence the shape of its cross sections. This relationship occurs both in cut marks produced with a formal tool (a burin) and with an unretouched flint flake. The active edge of a burin is a trihedral, and we have demonstrated that its level of penetration has a great influence on the open angle it forms (Figure 5b). The unretouched flint flake has an elongated active edge that can be used as a blade. This edge is composed of several functional units (elongated parts and small trihedral portions), which are responsible for the greater variability of the cross-section shape. The more a functional unit penetrates into the bone tissue, the more its structure will characterise the shape of the striations. This is the reason, apart from the wider open angle, shallower striations are more symmetrical and show more regular slopes (Figure 6).

The results obtained on the set of striations produced with the flint flake confirm that the correlation between shape and depth of the cross sections is valid, whatever type of functional unit of a cutting edge is used. This is an important result because we do not usually know the type of lithic implement used to produce cut marks identified in an archaeological sample. The relationship between DC and the shape of the cross-section slopes was not recognised in the cut marks produced with burins. This is probably due to the very regular shape of the active edges of these tools.

Finally, it has to be emphasised that some of the differences in shape found in the marks analysed in this work (shallow profiles with wide open angles vs deep profiles with narrow open angles) are similar to the differences in shape found by other authors in cuts inflicted using tools produced with different raw materials [7]. A more in-depth analysis of tool cutting edges should be carried out in order to understand their variability at a microscopic level and to identify any differences that depend on
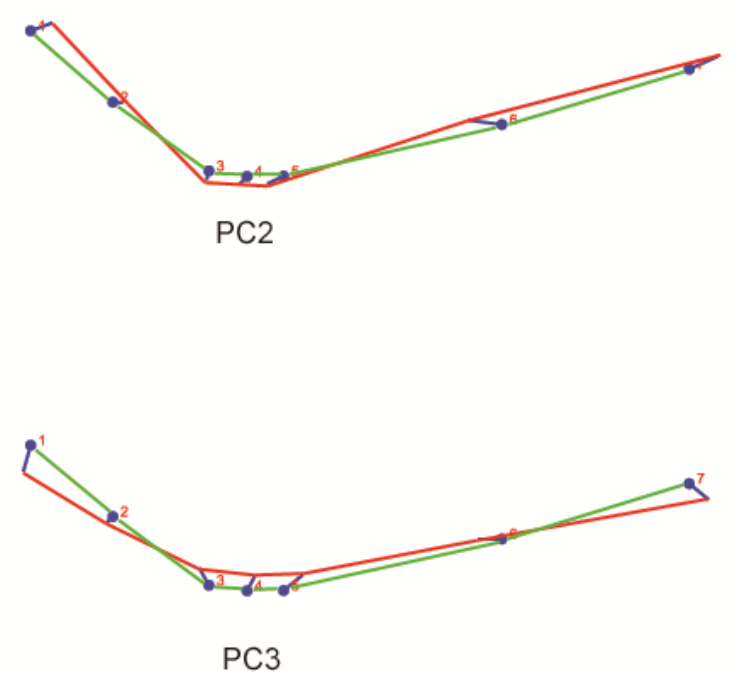

Figure 6.: Variability of shape of the slopes and opening angles described by PC2 and PC3, combining cut marks produced by burins and cut marks produced by the unretouched flake. 
the raw material used, the nature of the cutting edge (i.e. the specific functional part of the tool) or the presence/absence of a retouch. Since the study of marks on bones is of primary importance for the reconstruction of hominin behaviour in the past, e.g. [7], it is necessary to understand how the abovementioned parameters influence the penetrability of the tools into the bone tissue and, thus, the shape of cut marks.

\section{ACKNOWLEDGEMENT}

We would like to thank the two anonymous reviewers for their valuable comments, which improved the quality of the manuscript.

We are grateful to Daniele Aureli who produced the lithic tools used in our experimental program.

A special thanks to Owen Alexander Higgins for revising the English manuscript.

\section{REFERENCES}

[1] S. M. Bello, C. Soligo, A new method for the quantitative analysis of cutmark micromorphology, J. Archaeol. Sci. 35 (2008), pp. 1542-1552.

DOI: $10.1016 /$ j.jas.2007.10.018

[2] F. Boschin, J. Crezzini, Morphometrical analysis on cut marks using a 3D digital microscope, Int. J. Osteoarchaeol. 22 (2012), pp. 549-562. DOI: $10.1002 /$ oa.1272

[3] J. Crezzini, F. Boschin, U. Wierer, P. Boscato, Wild cats and cut marks: exploitation of Felis silvestris in the Mesolithic of Galgenbühel/Dos de la Forca (South Tyrol, Italy), Quatern. Int. 330 (2014), pp. 52-60.

DOI: $10.1016 /$ j.quaint.2013.12.056

[4] E. Moretti, S. Arrighi, F. Boschin, J. Crezzini, D. Aureli, A. Ronchitelli, Using 3D microscopy to analyze experimental cut marks on animal bones produced with different stone tools, Ethnobiology Letters 6 (2015), pp. 267-275.

DOI: $10.14237 /$ ebl.6.1.2015.349

[5] L. A. Courtenay, J. Yravedra, R. Huguet, A. Ollé, J. Aramendi, M. Á. Maté-González, D. Gónzalez-Aguilera, New taphonomic advances in 3D digital microscopy: a morphological characterisation of trampling marks, Quatern. Int. 517 (2019), pp. 55-66.

DOI: $10.1016 /$ j.quaint.2018.12.019

[6] A. Souron, A. Napias, T. Lavidalie, F. Santos, R. Ledevin, J-C. Castel, S. Costamagno, D. Cusimano, S. Drumheller, J. Parkinson, L. Rozada, D. Cochard, A new geometric morphometrics-based shape and size analysis discriminating anthropogenic and nonanthropogenic bone surface modifications of an experimental data set, 2019 IMEKO TC4 International Conference on Metrology for Archaeology and Cultural Heritage (MetroArchaeao 2019), Firenze, Italy, 4-6 December 2019, pp. 560-565. Online [accessed 22 March 2021] https://www.imeko.org/publications/tc4-Archaeo2019/IMEKO-TC4-METROARCHAEO-2019-109.pdf

[7] J. Yravedra, M. Á. Maté-González, J. F. Palomeque-González, J. Aramendi, V. Estaca-Gómez, M. S. J. Blazquez, E. García-Vargas, E. Organista, D. Gónzalez-Aguilera, M. C. Arriaza, L. CoboSánchez, A. Gidna, D. Uribelarrea Del Val, E. Barquedano, A. Mabulla, M. Domínquez-Rodrigo, A new approach to raw material use in the exploitation of animal carcasses at BK (Upper Bed II, Olduvai Gorge, Tanzania): a micro-photogrammetric and geometric morphometric analysis of fossil cut marks, Boreas (2017), pp. 860-873.

DOI: $10.1111 /$ bor. 12224

[8] S. M. Bello, R. Wallduck, S. A. Parfitt, C. B. Stringer, An Upper Palaeolithic engraved human bone associated with ritualistic cannibalism, PLoS ONE 12 (2017), e0182127.

DOI: 10.1371 /journal.pone.0182127
[9] R. Duches, N. Nannini, A. Fontana, F. Boschin, J. Crezzini, F. Bernardini, C. Tuniz, Archeological bone injuries by lithic backed projectiles: new evidence on bear hunting from the Late Epigravettian site of Cornafessa rock shelter (Italy), Archaeol. Anthropol. Sci. 11 (2019), pp. 2249-2270. DOI: $10.1007 / \mathrm{s} 12520-018-0674 y$

[10] M. A. Maté González, J. F. Palomeque-González, J. Yravedra, D. González-Aguilera, M. Domínguez-Rodrigo, Microphotogrammetric and morphometric differentiation of cut marks on bones using metal knives, quartzite and flint flakes, Archaeol. Anthropol. Sci. 4 (2016), pp. 805-816. DOI: $10.1007 / \mathrm{s} 12520-016-0401-5$

[11] A. Moroni, G. Boschian, J. Crezzini, G. Montanari-Canini, G. Marciani, G. Capecchi, S. Arrighi, D. Aureli, C. Berto, M. Freguglia, A. Araujo, S. Scaramucci, J. J. Hublin, T. Lauer, S. Benazzi, F. Parenti, M. Bonato, S. Ricci, S. Talamo, A. G. Segre, F. Boschin, V. Spagnolo, Late Neandertals in central Italy. Highresolution chronicles from Grotta dei Santi (Monte Argentario Tuscany), Quat. Sci. Rev. 217 (2019), pp. 130-151.

DOI: $10.1016 /$ j.quascirev.2018.11.021

[12] F. Boschin, Exploitation of carnivores, lagomorphs and rodents at Grotta Paglicci during the Epigravettian: the dawn of a new subsistence strategy?, J. Archaeol. Sci. Rep. 26 (2019), 101871. DOI: $10.1016 /$ j.jasrep.2019.101871

[13] M. A. Maté González, J. Yravedra, D. González-Aguilera, J. F. Palomeque-González, M. Domínguez-Rodrigo, Microphotogrammetric characterization of cut marks on bones, J. Archaeo. Sci. 62 (2015), pp. 128-142. DOI: $10.1016 /$ i.jas.2015.08.006

[14] M. A. Maté-González, J. Aramendi, J. Yravedra, R. Blasco, J. Rosell, D. González-Aguilera, M. Domínguez-Rodrigo, Assessment of statistical agreement of three techniques for the study of cut marks: 3D digital microscope, laser scanning confocal microscopy and micro-photogrammetry, J. Microsc. 267 (2017), pp. 356-370. DOI: $10.1111 /$ imi.12575

[15] J. Yravedra, E. García Vargas, M. A. Maté González, J. Aramendi, J. Palomeque-González, J. Vallés-Iriso, J. Matasanz-Vicente, D. González-Aguilera, M. Domínguez-Rodrigo, The use of microphotogrammetry and geometric morphometrics for identifying carnivore agency in bone assemblage, J. Archaeol. Sci. Rep. 14 (2017), pp. 106-115.

DOI: $10.1016 /$ j.jasrep.2017.05.043

[16] J. Yravedra, J. Aramendi, M. A. Maté-González, L. A. Courtenay, D. González-Aguilera, Differentiating percussion pits and carnivore tooth pits using $3 \mathrm{~d}$ reconstructions and geometric morphometrics, PLoS ONE 13 (2018), e0194324.

DOI: $10.1371 /$ journal.pone.0194324

[17] U. Wierer, S. Arrighi, S. Bertola, G. Kaufmann, B. Baumgarten, A. Pedrotti, P. Pernter, J. Pelegrin,2018. The Iceman's lithic toolkit: raw material, technology, typology and use. PLoS ONE 13 (2018), e0198292. DOI: $10.1371 /$ journal.pone.0198292

[18] F. J. Rohlf, TpsUtil, File Utility Program, Version 1.58, Department of Ecology and Evolution, State University of New York, Stony Brook, 2013.

[19] F. J. Rohlf, TpsDig, Digitize Landmarks and Outlines, Version 2.17, Department of Ecology and Evolution, State University of New York, Stony Brook, 2013.

[20] C. P. Klingenberg, MorphoJ: an integrated software package for geometric morphometrics, Mol. Ecol. Resour. 11 (2011), pp. $353-$ 357. DOI: $10.1111 /$ j.1755-0998.2010.02924.x

[21] A. Greenfield, The origin of metallurgy in the Central Balkans based on the analysis of cut marks on animal bones, Environ. Archaeol. 5 (2000), pp. 93-106. DOI: $10.1006 /$ jasc. 1998.0348 